\title{
Research on a real-time scanning tunneling microscope data acquisition system (Notice of Removal)
}

Chang Xu, Baoping Xiao, Lijun Xu

Chang Xu, Baoping Xiao, Lijun Xu, "Research on a real-time scanning tunneling microscope data acquisition system (Notice of Removal)," Proc. SPIE 6723, 3rd International Symposium on Advanced Optical Manufacturing and Testing Technologies: Optical Test and Measurement Technology and Equipment, 67233A (17 January 2008); doi: 10.1117/12.783484

SPIE Event: 3rd International Symposium on Advanced Optical Manufacturing and Testing Technologies: Large Mirrors and Telescopes, 2007, Chengdu, China 


\section{Research on a real-time scanning tunneling microscope data acquisition system (notice of removal)}

Proc. SPIE 6723, 67233A (2007); http://dx.doi.org/10.1117/12.783484

Online Publication Date: 27 November 2007

Retracted from Publication: 12 April 2010

Conference Date: 12 July 2007

Conference Location: Chengdu, China

Conference Title: 3rd International Symposium on Advanced Optical Manufacturing and Testing

Technologies: Optical Test and Measurement Technology and Equipment

Conference Chairs: J unhua Pan, James C. Wyant, Hexin Wang

Chang Xu and Lijun Xu

China Jiliang Univ. (China)

Baoping Xiao

China Jiliang Univ. (China) and Zhejiang Univ. (China)

This paper (67233A) was removed from the SPIE Digital Library on 13 April 2010 to discovery of plagiarism. As stated in the SPIE Guidelines for Professional Conduct and Publishing EthicS, SPIE defines plagiarism as the reuse of someone else's prior ideas, processes, results, or words without explicit attribution of the original author and source, or falsely representing someone else's work as one's own. SPIE considers plagiarism in any form, at any level, to be unacceptable and a serious breach of professional conduct. It is SPIE policy to remove such papers and to take appropriate corrective or disciplinary action against the offending author(s). 